\title{
Comparison of Combination Therapy of Olmesartan plus Azelnidipine or Hydrochlorothiazide on Renal and Vascular Damage in SHR/NDmcr-cp Rats
}

\author{
Hajime Nagasu Minoru Satoh Daisuke Yorimitsu Naruya Tomita \\ Tamaki Sasaki Naoki Kashihara \\ Department of Nephrology and Hypertension, Kawasaki Medical School, Kurashiki, Japan
}

\section{Key Words}

Azelnidipine $\cdot$ Calcium channel blockers $\cdot$ Chronic kidney disease $\cdot$ Combination therapy $\cdot$ Angiotensin receptor blockers $\cdot$ Hydrochlorothiazide $\cdot \mathrm{NAD}(\mathrm{P}) \mathrm{H}$ oxidase activity · Olmesartan - Renal and vascular damage $\cdot$ SHR/NDmcr-cp rats

\begin{abstract}
Background: Although the recommended target blood pressure for patients with chronic kidney disease is $<130 / 80$ $\mathrm{mm} \mathrm{Hg}$, this is difficult to achieve by treatment with an angiotensin receptor blocker alone. Addition of either a calcium channel blocker or a diuretic is suggested as second-line medication; however, which combination is most beneficial for target-organ protection remains unknown. Methods: SHR/NDmcr-cp rats were administered no medications (control) or low-dose olmesartan for 2 weeks and then either olmesartan at an increased dose, azelnidipine, or the hydrochlorothiazide for 3 weeks. We assessed oxidative stress in the kidney and aorta, and endothelial function. Results: Urinary protein excretion was lower in all treated rats than in control rats. Oxidative stress caused by activation of $\mathrm{NAD}(\mathrm{P}) \mathrm{H}$ oxidase was observed in the glomeruli and aorta of control rats and was significantly suppressed in the olmesar-
\end{abstract}

tan/azelnidipine (Olm/Azl) groups. Combination therapy with olmesartan and hydrochlorothiazide (OIm/HCTZ) however failed to suppress oxidative stress. The Olm/Azl groups maintained the endothelial surface layer in the glomeruli and protected endothelial function in the aorta. Conclusion: In an animal model of metabolic syndrome, a combination of Olm/Azl is superior to a combination of Olm/HCTZ in terms of prevention of glomerular and vascular injuries.

Copyright $\odot 2011$ S. Karger AG, Basel

\section{Introduction}

The prevalence of hypertension in the adult population is estimated to be 20 and $6-15 \%$ in developed and developing countries, respectively [1]. Additionally, with the increasing prevalence of diabetes, hypertension, and obesity, the prevalence of chronic kidney disease (CKD) has increased, affecting several million people worldwide [2]. Angiotensin receptor blockers (ARBs), which inhibit the renin-angiotensin system (RAS) and are used for the treatment of CKD, have been shown to have a renoprotective effect [3]. These drugs decrease proteinuria and retard disease progression to end-stage renal disease [4]. Although the target blood pressure for patients with CKD

\section{KARGER \\ Fax +4161306 1234 E-Mail karger@karger.ch} www.karger.com

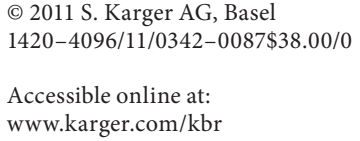

Hajime Nagasu, MD

Department of Nephrology and Hypertension

Kawasaki Medical School

577 Matsushima, Kurashiki, Okayama 701-0192 (Japan)

E-Mail zajiten1@gmail.com 
is $<130 / 80 \mathrm{~mm} \mathrm{Hg}$, this target cannot be achieved in many patients by treatment with a single drug, and multidrug therapy is often required [5].

Most clinical trials involving patients with hypertension who are at high risk for cardiovascular events have shown that treatment with multiple antihypertensive medications is necessary to attain recommended blood pressure goals [6]. Additional administration of either a calcium channel blocker (CCB) or diuretic has been suggested as second-line therapy following an ARB [7]; however, which combination therapy is most beneficial in terms of protection of pivotal organs remains unknown. Nemeth et al. [8] reported that mineralocorticoid receptor blockade provides additional renoprotection compared with angiotensin-converting enzyme inhibition monotherapy. Diuretics have an enhanced antiproteinuric effect when combined with ARBs [9]. In the ACCOMPLISH study, however, concomitant use of RAS inhibitors and CCBs more effectively reduced cardiovascular events than did concomitant use of RAS inhibitors and diuretics [10]. In the present study, we attempted to determine the efficacy of high-dose ARB (olmesartan) monotherapy, ARB plus CCB (azelnidipine, which suppresses sympathetic nerve activity), and ARB plus diuretics in the prevention of organ damage including kidney injuries and endothelial dysfunction in SHR/NDmcr-cp rats, which provide an animal model for metabolic syndrome.

\section{Materials and Methods}

\section{Experimental Protocol}

The experimental protocol (No. 08-080) was approved in advance by the Ethics Review Committee for Animal Experimentation of the Kawasaki Medical School, Kurashiki, Japan. Male 7-week-old SHR/NDmcr-cp rats, weighing 230-240 g, were purchased from Japan SLC (Hamamatsu, Japan). These animals have previously been used as a model of metabolic syndrome [11, 12]. The animals were housed in a temperature- and humidity-controlled room with a 14:10 h light-dark cycle; they were fed standard laboratory animal chow and had free access to tap water. This protocol was approved by the Standard Operating Procedure of the Kawasaki Medical School, Kurashiki, Japan. The rats were divided into two groups: those treated with drugs (intervention group, $\mathrm{n}=24$ ) and those not treated with drugs (control group $(\mathrm{Con}), \mathrm{n}=8)$. Rats in the intervention group received the ARB olmesartan $(\mathrm{Olm})$ at $1 \mathrm{mg} / \mathrm{kg} /$ day for 2 weeks and then either (a) Olm at an increased dose of $6 \mathrm{mg} / \mathrm{kg} /$ day (High-Olm, $\mathrm{n}=8$ ) [13], (b) Olm at the same dose plus the CCB azelnidipine at $3 \mathrm{mg} /$ $\mathrm{kg} /$ day $(\mathrm{Olm} / \mathrm{Azl}, \mathrm{n}=8)$ [14], or (c) Olm at the same dose plus the diuretic hydrochlorothiazide at $10 \mathrm{mg} / \mathrm{kg} /$ day $(\mathrm{Olm} / \mathrm{HCTZ}, \mathrm{n}=$ $8)$. The dosage of each drug was selected to give the same degree of blood pressure lowering. During the experimental period, body weight was measured weekly in each rat. The rats were subjected to a 24-hour fast in metabolic cages to collect urine samples. After 3 weeks, the rats were killed and blood samples were obtained with an 18-gauge needle inserted into the left ventricle. The abdominal aorta was cannulated, and the kidney was perfused in a retrograde manner, with ice-cold phosphate-buffered saline $(\mathrm{pH}$ 7.4). One-quarter of each removed kidney was immersed and fixed in $4 \%$ paraformaldehyde and then embedded in paraffin for periodic acid-Schiff staining and one quarter was frozen-fixed for immunohistochemistry. The remaining half of each removed kidney was cut into small pieces, and the glomeruli were isolated for protein and RNA extraction, superoxide measurement, and $\mathrm{NAD}(\mathrm{P}) \mathrm{H}$ oxidase activity assay using the mechanical gradedsieving technique. After isolation, the purity of the final suspension was determined by light microscopy. The average tubular contamination was $4.8 \pm 0.4 \%$.

\section{Physiologic and Biochemical Measurements}

Systolic arterial blood pressure was measured using the tailcuff method at an ambient temperature of $37^{\circ} \mathrm{C}$ (BP-98A; Softron, Tokyo, Japan) [15]. Urine was collected and blood samples were obtained immediately after the rats were killed. Serum creatinine and $24 \mathrm{~h}$ urinary creatinine and albumin concentrations were measured using an enzyme-linked immunosorbent assay kit (Exocell, Philadelphia, Pa., USA) [16].

\section{Detection of Superoxide in Glomeruli}

Superoxide production was detected by $2^{\prime}, 7^{\prime}$-dichlorofluorescein (DCF) staining [13]. Isolated glomeruli from each group were incubated with RPMI-1640 medium containing $20 \mathrm{mM} \mathrm{2} 2^{\prime}, 7^{\prime}$ dichlorofluorescein diacetate (DCFH-DA; Molecular Probes, Eugene, Oreg., USA) for $10 \mathrm{~min}$, and then rinsed with phosphatebuffered saline. Fluorescent images were obtained using a confocal laser microscope (Leica Microsystems, Tokyo, Japan) at excitation/emission wavelengths of $485 / 535 \mathrm{~nm}$ for DCF. The fluorescence intensity values from 100 different isolated glomeruli in each group were calculated by Leica TCS-NT software (Leica Microsystems) and the average values are presented.

\section{Measurement of $\mathrm{NAD}(\mathrm{P}) \mathrm{H}$ Oxidase Activity in Isolated \\ Glomeruli and Aortic Endothelium}

$\mathrm{NAD}(\mathrm{P}) \mathrm{H}$ oxidase activities in glomeruli and the aorta were measured using tiron-inhibitable lucigenin chemiluminescence, as previously described [17]. Lucigenin chemiluminescence was expressed in $\mathrm{U} / \mathrm{min} / \mathrm{mg}$.

\section{RNA Isolation and Real-Time Quantitative PCR}

Total RNA was isolated from the glomeruli with TRIzol (Invitrogen Japan, Tokyo, Japan). Reverse transcriptase reactions were performed using a Ready-To-Go T-Primed First-Strand kit (GE Healthcare Bio-Sciences, Tokyo, Japan) for first-strand cDNA synthesis. Real-time quantitative PCR was performed using the ABI Prism 7700 sequence-detection system (Applied Biosystems, Foster City, Calif., USA). Primers and probes for TaqMan analysis were designed using Primer Express 1.5 (Applied Biosystems) with information from the supplier based on the sequence information from GenBank or Expressed Sequence Tag (EST) databases. The primers and probes used for gp91phox, p22phox, p47phox and p67phox (where phox indicates phagocyte oxidase) are described in our previous study [18]. 
Table 1. Physiologic and biochemical data

\begin{tabular}{lcccc}
\hline & Control & High-Olm & Olm/Azl & Olm/HCTZ \\
\hline Systolic blood pressure, mm Hg & $180 \pm 5$ & $141 \pm 7^{\mathrm{a}}$ & $130 \pm 9^{\mathrm{a}}$ & $137 \pm 5^{\mathrm{a}}$ \\
Heart rate, beats/min & $453 \pm 7$ & $399 \pm 22$ & $364 \pm 18^{\mathrm{a}}$ & $408 \pm 7$ \\
Serum BUN, mg/dl & $33.5 \pm 0.5$ & $35.1 \pm 1.1$ & $30.7 \pm 1.3$ & $37.2 \pm 2.0^{\mathrm{b}}$ \\
Plasma glucose, mg/dl & $162 \pm 22$ & $158 \pm 18$ & $164 \pm 12$ & $166 \pm 10$ \\
Triglyceride, mg/dl & $632 \pm 15$ & $601 \pm 14$ & $598 \pm 25$ & $621 \pm 22$ \\
U-Na expression, g/day & $0.79 \pm 0.20$ & $0.78 \pm 0.03$ & $0.99 \pm 0.10$ & $1.63 \pm 0.16^{\mathrm{a}, \mathrm{b}}$ \\
U-Pro/U-CRN, g/g·CRN & $1.36 \pm 0.28$ & $0.30 \pm 0.01^{\mathrm{a}}$ & $0.30 \pm 0.02^{\mathrm{a}}$ & $0.38 \pm 0.03^{\mathrm{a}}$ \\
\hline
\end{tabular}

BUN = Blood urea nitrogen; U-Pro = urinary protein; $\mathrm{U}-\mathrm{CRN}=$ urinary creatinine. Data are expressed as mean \pm SEM. $\mathrm{n}=8$ in each group. ${ }^{\mathrm{a}} \mathrm{p}<0.05$ vs. control, ${ }^{\mathrm{b}} \mathrm{p}<0.05$ vs. Olm/Azl.

\section{Histopathologic and Immunohistochemical Examination}

Sections (thickness $4 \mu \mathrm{m}$ ) were prepared from renal tissue samples embedded in paraffin, and stained by periodic acidSchiff. Tissue sections were also processed for immunohistochemical examination for desmin staining. Two pathologists, blinded to the treatment conditions, performed semiquantitative analysis of stained sections. The net score for each rat was taken as the average of the scores obtained for that rat by two nephrologists. A goat anti-desmin polyclonal antibody (sc-34200; Santa Cruz Biotechnology, Santa Cruz, Calif., USA) was used as the primary antibody. Expression of desmin was graded semiquantitatively according to the degree of positive staining in the glomeruli $(0=0-5 \%,+1=$ $5-25 \%,+2=25-50 \%,+3=50-75 \%,+4=75-100 \%)$, and the mean score per section (50 glomeruli) was calculated (each group $n=5$ ) [19]. Glomerular glycocalyx was detected by lectin staining. Paraffin-embedded specimens were stained with tetramethylrhodamine isothiocyanate-conjugated wheat germ agglutinin (WGA) lectin, which binds to sugar residues, sialic acid, and $\mathrm{N}$-acetylglucosaminyl residues of glycoproteins. WGA-stained kidney sections were analyzed using TCS-NT ${ }^{\mathrm{TM}}$ system software (Leica). The glomerular endothelial surface layer was also evaluated by the WGA staining score with respect to the amount of degradation as follows: 0 , none; 1 , mild; 2 , moderate; 3 , severe; 4 , global degradation. At least 50 glomeruli were randomly selected from each rat and the mean score was calculated [20].

\section{Endothelium-Dependent Vascular Responses}

Thoracic aortic ring preparations were obtained from each group. Cylindrical segments (length $3 \mathrm{~mm}$ ) were cut from the aorta and were bathed in $5 \mathrm{ml}$ Krebs bicarbonate saline equilibrated with $95 \% \mathrm{O}_{2}-5 \% \mathrm{CO}_{2}$, and maintained at $37^{\circ} \mathrm{C}$. The rings were suspended under $1 \mathrm{~g}$ of tension and preconstricted by adding $3 \times$ $10^{-7} \mathrm{M}$ norepinephrine. After the contraction force had reached a plateau, acetylcholine $\left(10^{-9}\right.$ to $\left.10^{-5} \mathrm{M}\right)$ was added incrementally to the bath. The force of isometric contraction was measured using a force-displacement transducer (Model MTOB-1Z; Labo Support, Osaka, Japan). Responses to acetylcholine were expressed as the percentage of the precontracted tension induced by norepinephrine, as previously described [21]. Nonlinear regression (GraphPad Prism 5.0; GraphPad Software, La Jolla, Calif., USA) was used to determine $-\log _{10}$ half-maximal effective concentration $\left(\mathrm{pEC}_{50}\right)$ and maximum responses $\left(\mathrm{R}_{\max }\right)$ to acetylcholine in each ring.

ARB/CCB Combination Therapy Effective

in a Metabolic Syndrome Rat Model
Measurement of Kidney Norepinephrine Concentration

Kidney tissue was sonicated in $0.5 \mathrm{ml}$ buffer ( $\mathrm{pH} 4.0$ ) containing $0.17 \mathrm{M}$ citrate acetate and $10 \%$ methanol. The sonicated mixture was centrifuged, and the clear aspirate was subjected to microfiltration before measurement of norepinephrine concentration using an enzyme-linked immunosorbent assay.

Effects on $N A D(P) H$ Oxidase Activity Induced by High

Glucose

We used human glomerular endothelial cells (hGECs), passage 6-8 (Cell Systems Corp., Kirkland, Wash., USA). Cells were cultured on 10-cm dishes and propagated in Dulbecco's modified Eagle's medium supplemented with 5\% heat-inactivated newborn bovine serum, $100 \mathrm{U} / \mathrm{ml}$ penicillin, and $100 \mu \mathrm{g} / \mathrm{ml}$ streptomycin. Cells were incubated at $37^{\circ} \mathrm{C}$ in a humidified atmosphere of $95 \%$ air-5\% $\mathrm{CO}_{2}$. The hGECs were incubated in different media as follows: (1) constant normal glucose medium (5 mM); (2) constant high-glucose medium (30 mM); (3) high-glucose medium + Olm $10^{-9} \mathrm{M}$; (4) Olm $10^{-9} \mathrm{M}+\mathrm{Azl} 10^{-6} \mathrm{M}$, and (5) Olm $10^{-9} \mathrm{M}+\mathrm{HCTZ}$ $10^{-6} \mathrm{M}$. Cells were incubated for $1 \mathrm{~h}$ after each drug addition. After incubation, $\mathrm{NAD}(\mathrm{P}) \mathrm{H}$ oxidase activity was measured using a lucigenin chemiluminescence assay.

Statistical Analysis

Values are expressed as mean \pm SEM. Statistical comparisons were made using the Mann-Whitney U test or the one-factor analysis of variance with a Tukey-Kramer test for multiple comparisons. p values $<0.05$ were considered significant.

\section{Results}

\section{Physiological Data}

All rats treated with either High-Olm, Olm/Azl, or $\mathrm{Olm} / \mathrm{HCTZ}$ showed a similar degree of decrease in blood pressure (table 1). However, only the rats treated with $\mathrm{Olm} /$ Azl had significantly lower heart rates than untreated controls. Urinary protein excretion was significantly lower, to a similar degree, in all treated groups than in the 


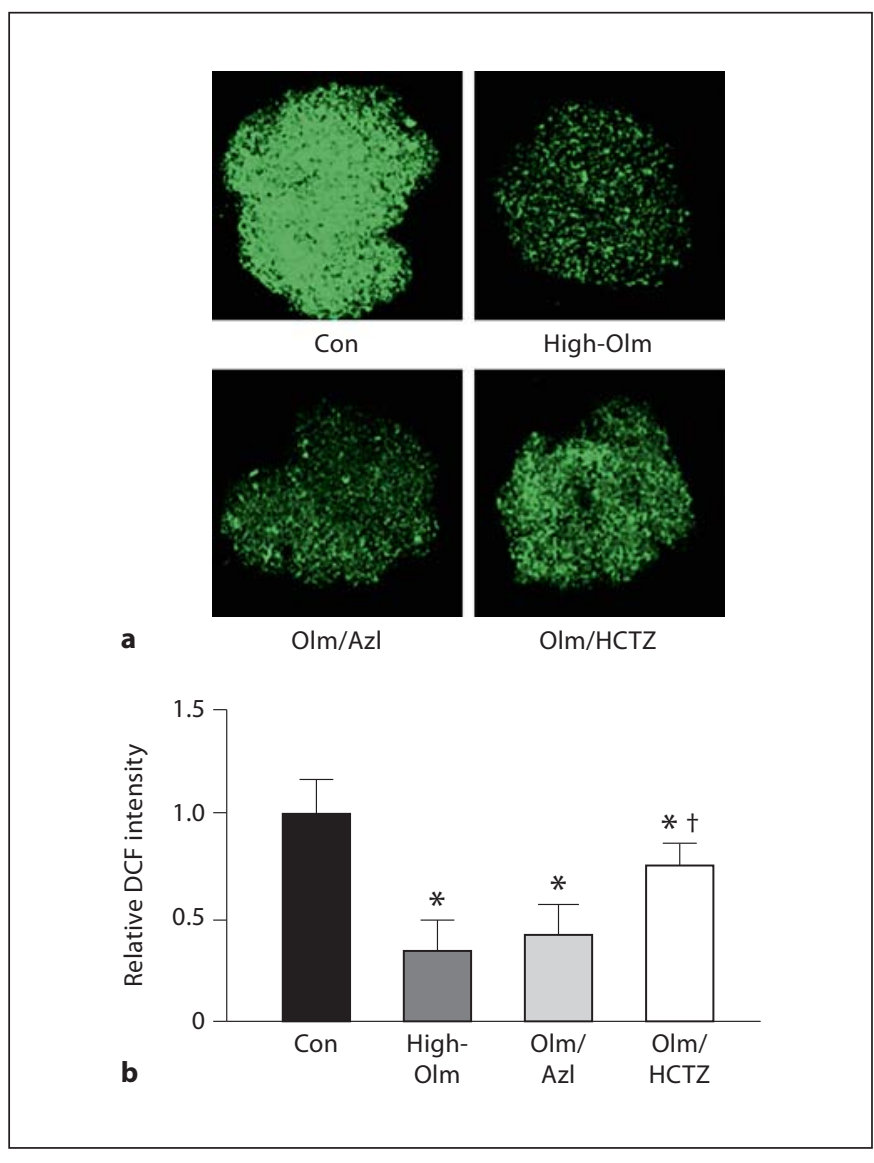

Fig. 1. Glomerular ROS production in the rat model of metabolic syndrome. a Representative glomerular DCFH staining for ROS production. b Relative DCF intensity. $\mathrm{n}=50$ in each group. ${ }^{*} \mathrm{p}<$ 0.05 vs. control (Con), ${ }^{\dagger} \mathrm{p}<0.05$ vs. Olm/Azl.

control group. Only in the Olm/HCTZ group was urinary sodium excretion higher than in the control group. The Olm/HCTZ group was also the only group with blood urea nitrogen levels higher than the control group.

\section{Glomerular Reactive Oxygen Species Production and}

$N A D(P) H$ Oxidase Activity

Oxidation of DCFH to the fluorescent compound DCF was used as a qualitative marker of cellular oxidative stress. Figure la shows representative isolated glomerular fluorescence images in each group. The DCF fluorescence intensity in the isolated glomeruli in all treated groups was weaker than that in the control group (fig. 1b). However, the DCF fluorescence intensity in glomeruli in the $\mathrm{Olm} / \mathrm{HCTZ}$ group was significantly stronger than

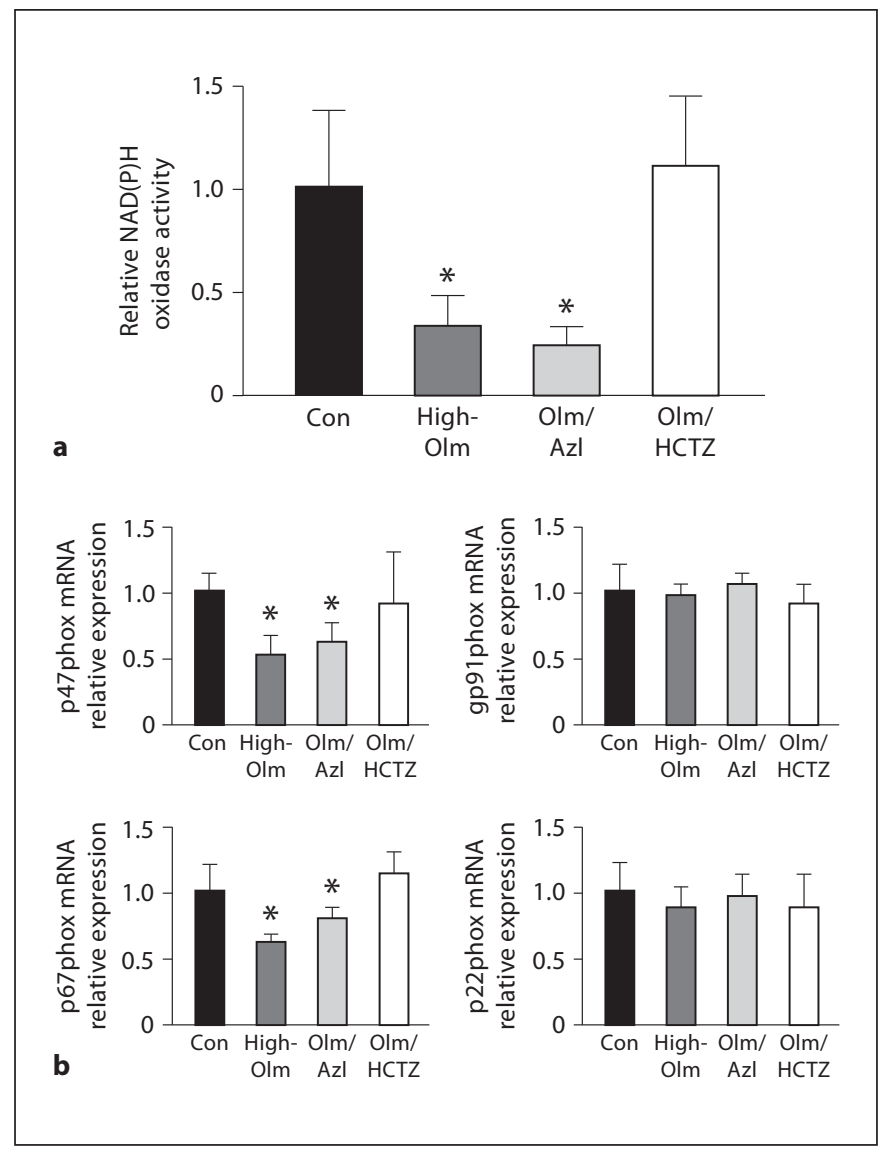

Fig. 2. $\mathrm{NAD}(\mathrm{P}) \mathrm{H}$ oxidase activity in isolated glomeruli from rats with metabolic syndrome. a Glomerular NAD(P)H oxidase activity determined by tiron-inhibitable lucigenin assay $(n=5$ in each group). ${ }^{*} \mathrm{p}<0.05$ vs. control (Con). b mRNA levels of $\mathrm{p} 47 \mathrm{phox}$, p67phox, gp91phox, and p22phox in each rat were measured by quantitative real-time PCR. ${ }^{*} \mathrm{p}<0.05$ vs. control (Con).

that in the Olm/Azl group (Con $1.00 \pm 0.20$-fold, High-Olm $0.41 \pm 0.11$-fold, Olm/Azl $0.46 \pm 0.12$-fold, Olm/HCTZ $0.71 \pm 0.07$-fold, $\mathrm{p}<0.05$ vs. Olm/Azl). $\mathrm{NAD}(\mathrm{P}) \mathrm{H}$ oxidase activity in isolated glomeruli was also determined using the lucigenin chemiluminescence assay (fig. 2a). ROS production by $\mathrm{NAD}(\mathrm{P}) \mathrm{H}$ oxidase was significantly lower in the High-Olm and Olm/Azl groups than in the control group (Con $1.00 \pm 0.41$-fold, HighOlm $0.31 \pm 0.18$-fold, $\mathrm{p}<0.05$ vs. Con; Olm/Azl $0.25 \pm$ 0.08 -fold, $\mathrm{p}<0.05$ vs. Con), but not in the Olm/HCTZ group (1.11 \pm 0.36 -fold). p22phox and gp91phox are membrane components, whereas p47phox and p67phox are cytosolic components of $\mathrm{NAD}(\mathrm{P}) \mathrm{H}$ oxidase. Expression of mRNAs of both cytosolic components was significantly decreased in isolated glomeruli from Olm/Azl 


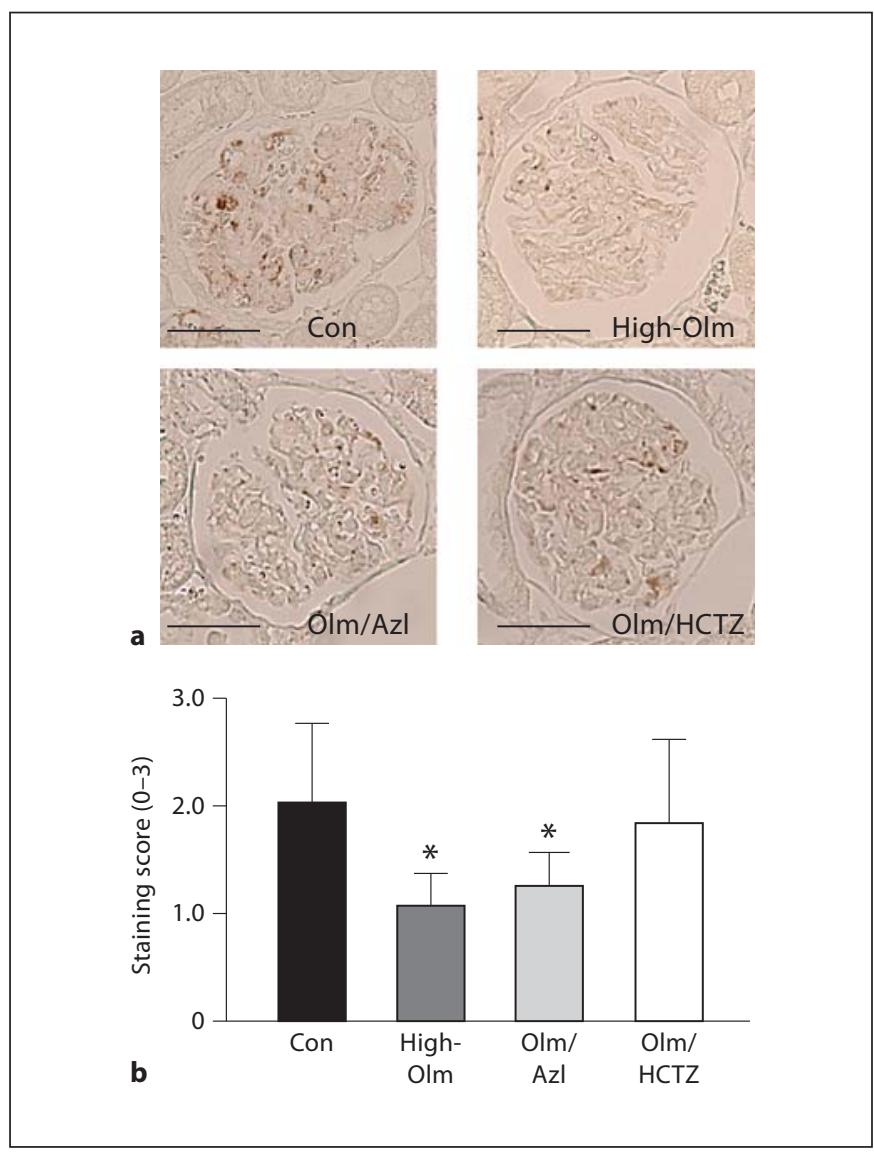

Fig. 3. Podocyte injury in the rat model of metabolic syndrome. a Representative glomerular desmin immunostaining for evaluation of podocyte injury. Bar $=50 \mu \mathrm{m}$. b Desmin staining score. The mean score per section (50 glomeruli) was calculated $(\mathrm{n}=5$ sections in each group). ${ }^{*} \mathrm{p}<0.05$ vs. control (Con).

animals compared with Con and Olm/HCTZ animals. By contrast, expression of mRNAs of the membrane components did not significantly differ between the groups (fig. 2b). These results suggest that Olm/Azl and HighOlm but not Olm/HCTZ decreased superoxide production by reducing $\mathrm{NAD}(\mathrm{P}) \mathrm{H}$ oxidase activation in glomeruli to a similar degree.

\section{Detection of Podocyte Injury by Desmin Staining}

Histologically, no major changes were observed in the glomeruli or tubulointerstitial regions in any group. However, increased desmin staining of glomeruli, indicating podocyte injury in this model, was observed in the untreated control animals. The desmin staining was significantly less intense in the High-Olm and Olm/Azl

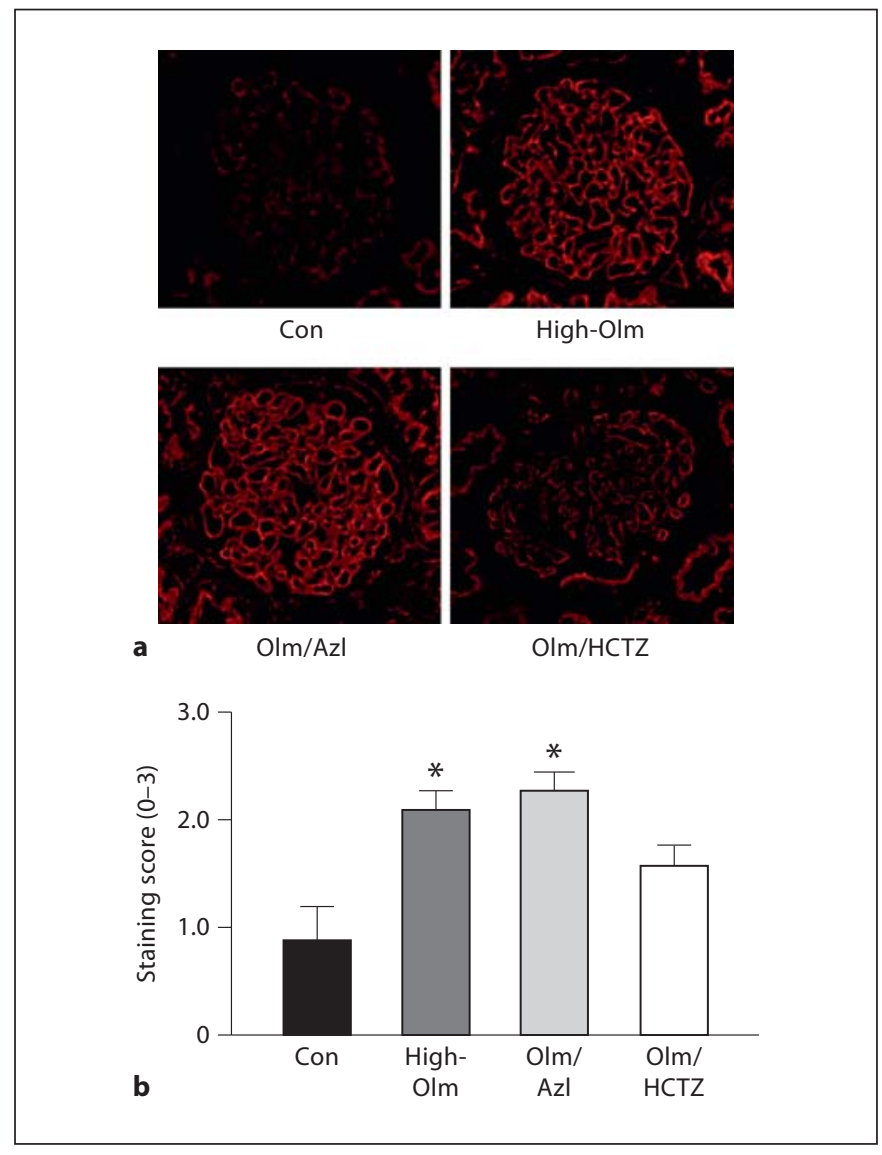

Fig. 4. Evaluation of glycocalyx in capillary walls by WGA staining. a Representative glomerular WGA immunostaining for evaluation of podocyte injury. Bar $=50 \mu \mathrm{m}$. b WGA staining score. The mean score per section (50 glomeruli) was calculated ( $\mathrm{n}=5$ sections in each group). ${ }^{*} \mathrm{p}<0.05$ vs. control (Con).

groups than in the Con group (fig. 3a, b). The score of glomerular desmin staining was significantly lower in the High-Olm and Olm/Azl groups than in the Con group, although the staining score was not lower in the Olm/HCTZ group.

\section{Detection of Glomerular Glycocalyx by WGA Lectin Staining}

WGA lectin was observed on the glomerular loop including endothelial cells, podocytes, and the glomerular basement membrane in Con rats. The degree of WGA disarray was examined semiquantitatively using a scoring system. WGA lectin staining was preserved in glomeruli from Olm/Azl more than from Olm/HCTZ animals (fig. 4a, b). 


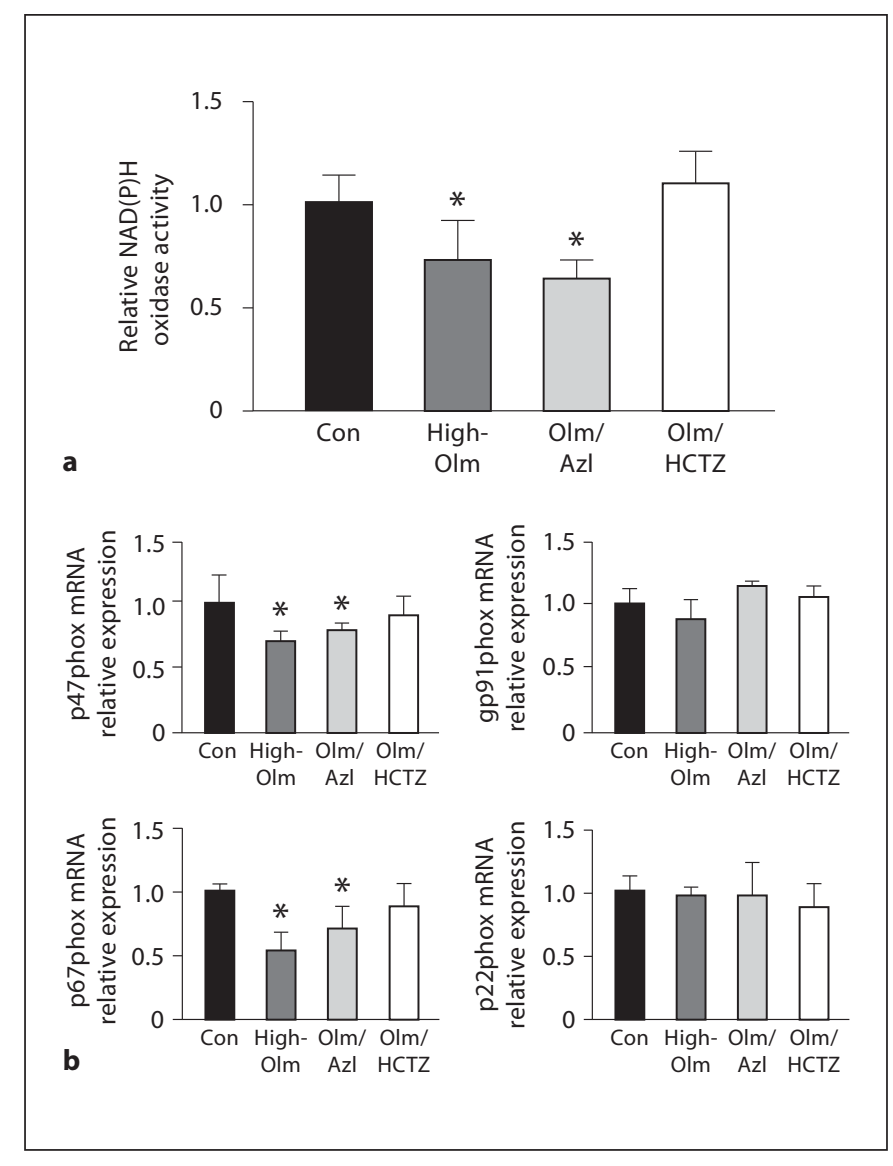

Fig. 5. Aortic $\mathrm{NAD}(\mathrm{P}) \mathrm{H}$ oxidase activity and endothelial function in the rat model of metabolic syndrome. a Aortic NAD(P)H oxidase activity determined by tiron-inhibitable lucigenin assay. ${ }^{*} \mathrm{p}<0.05$ vs. control (Con). b Expression of mRNA for NAD $(\mathrm{P})$ $\mathrm{H}$ oxidase components in aortas from each rat. The mRNA levels of p47phox, p67phox, gp91phox, and p22phox in each rat were measured by quantitative real-time PCR. ${ }^{*} \mathrm{p}<0.05$ vs. control (Con).

\section{Endothelial Dysfunction in Aorta}

The NAD $(\mathrm{P}) \mathrm{H}$ oxidase activity in the thoracic aorta was significantly lower in the High-Olm and Olm/Azl groups than in the Con group (fig. 5a), however it was not significantly lower in the Olm/HCTZ group. Expression of mRNAs of both cytosolic components was also significantly decreased in aorta from Olm/Azl animals compared with Con and Olm/HCTZ animals (fig. 5b). The data on endothelium-dependent vascular response is summarized in figure 6 . Acetylcholine caused concentration-dependent vasorelaxation in aortic rings from the Con group ( $\mathrm{pEC}_{50} 7.2 \pm 0.1 ; \mathrm{R}_{\max } 60 \pm 8 \%$ ). High-Olm and $\mathrm{Olm} /$ Azl significantly improved endothelial dysfunction in this rat model of metabolic syndrome. The

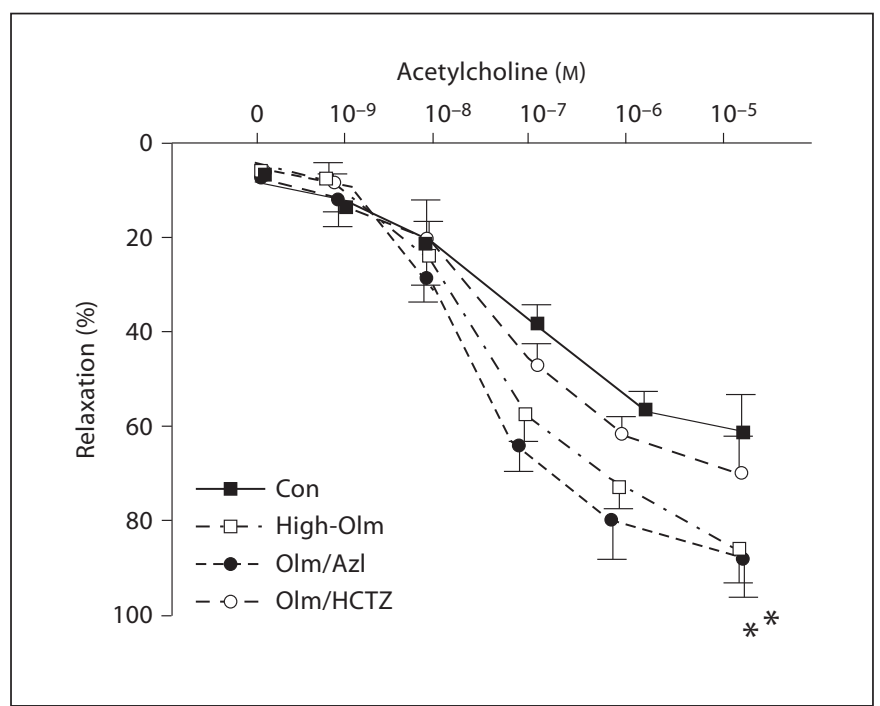

Fig. 6. Aortic endothelial function in the rat model of metabolic syndrome. Thoracic aortic rings were prepared from the rat aortas. Norepinephrine was applied to achieve near-maximal contraction, and responses to acetylcholine at the indicated concentrations were determined. Relaxation was expressed as the percent of the pre-contraction tension induced by norepinephrine ( $\mathrm{n}=5$ in each group). ${ }^{*} \mathrm{p}<0.05$ vs. control (Con).

maximum relaxation was significantly higher in the High-Olm and Olm/Azl groups $\left(\mathrm{R}_{\max } 88 \pm 6\right.$ and $89 \pm$ $8 \%$, respectively) than in the Con group. By contrast, the maximum relaxation in the Olm/HCTZ group $\left(\mathrm{R}_{\max } 69\right.$ $\pm 7 \%$ ) was not significantly higher than that in the Con group. Endothelial sensitivity to acetylcholine did not differ between the groups ( $\mathrm{pEC}_{50}$ : Con $7.0 \pm 0.2$; HighOlm $7.1 \pm 0.1 ;$ Olm/Azl 7.1 $\pm 0.1 ; \mathrm{Olm} / \mathrm{HCTZ} 7.2 \pm 0.3)$.

\section{Sympathetic Activity Assessed by Urinary and Kidney Norepinephrine}

Azl and the ARB olmesartan suppress sympathetic nerve activity. Therefore we determined systemic and renal sympathetic nerve activity. High-Olm and Olm/Azl significantly suppressed both urinary and kidney norepinephrine concentrations compared with the non-treated Con group (fig. 7a, b). However, renal sympathetic activity was not suppressed in the Olm/HCTZ group.

\section{In vitro Antioxidative Effects of Azl/Olm on Human Endothelial Cells}

Glucose at $30 \mathrm{~mm}$ induced an increase in $\mathrm{NAD}(\mathrm{P}) \mathrm{H}$ oxidase activity in hGECs (fig. 8). Low-dose olmesartan $\left(10^{-9} \mathrm{M}\right)$ was associated with a decrease in NAD $(\mathrm{P}) \mathrm{H}$ oxi- 


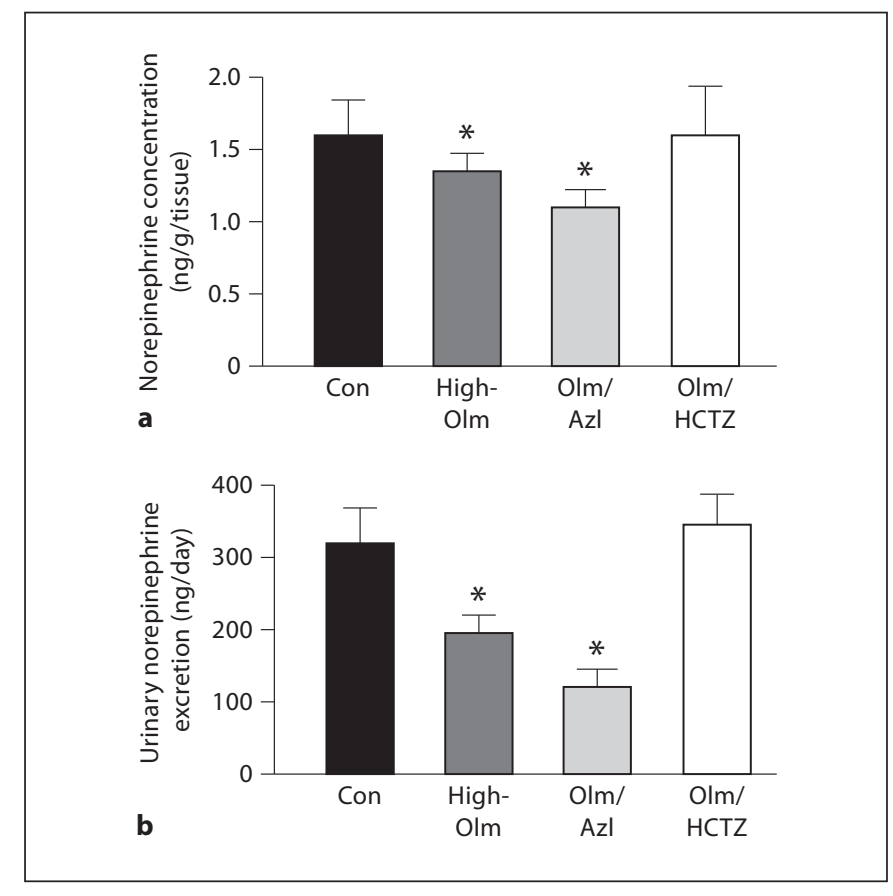

Fig. 7. Renal tissue norepinephrine concentrations. a Norepinephrine concentrations were lower in the High-Olm and Olm/ Azl groups than in the Con group. b Urinary norepinephrine excretion was measured at 12 weeks ( $\mathrm{n}=5$ in each group). ${ }^{*} \mathrm{p}<0.05$ vs. control (Con).

dase activity, but the change was not significant. The addition of Azl was associated with a significant decrease in $\mathrm{NAD}(\mathrm{P}) \mathrm{H}$ oxidase activity, whereas the addition of HCTZ was associated with no apparent change in $\mathrm{NAD}(\mathrm{P}) \mathrm{H}$ oxidase activity.

\section{Discussion}

In this study, we explored which therapy, a high-dose $A R B$ monotherapy or combination of an ARB/CCB or $\mathrm{ARB} /$ diuretic, is most beneficial for organ protection in a rat model of metabolic syndrome. Blood pressure was lowered and proteinuria reduced to the same degree in all the treatment groups. Olm/Azl and High-Olm successfully decreased ROS production apparently by suppressing $\mathrm{NAD}(\mathrm{P}) \mathrm{H}$ oxidase activity in glomeruli and endothelial cells of the thoracic aorta, to approximately the same degree. We could not detect these effects with $\mathrm{Olm} /$ HCTZ. Our in vitro results indicate that high-Olm and Olm/Azl directly suppress activation of NAD $(\mathrm{P}) \mathrm{H}$ oxidase induced by high glucose in hGECs. These results

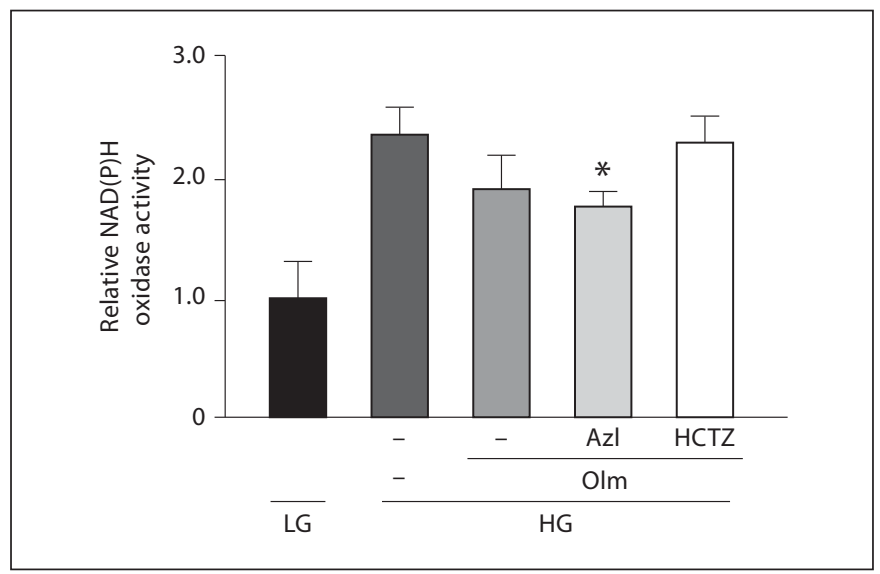

Fig. 8. High glucose-induced $\mathrm{NAD}(\mathrm{P}) \mathrm{H}$ oxidase activity of hGECs. Endothelial NAD(P)H oxidase activity determined by tiron-inhibitable lucigenin assay ( $\mathrm{n}=5$ in each group). $\mathrm{LG}=$ Low glucose; HG = high glucose. ${ }^{*} \mathrm{p}<0.05$ vs. HG/Olm (-).

indicate that the combination of an ARB and CCB may be superior to the combination of an ARB and diuretic to prevent tissue injuries caused by oxidative stress in rats with a condition similar to metabolic syndrome.

Our results suggest that Azl decreased ROS more than HCTZ in glomeruli and the aorta. Some CCBs have a potential to reduce cardiovascular events by improving endothelial function via an antioxidative effect. Azl is reported to have an antioxidative effect on endothelial cells and in kidney [22-24]. Oxidative stress is widely recognized to be involved in the development of endothelial dysfunction and progression of atherosclerosis $[25,26]$. In the vascular wall, $\mathrm{NAD}(\mathrm{P}) \mathrm{H}$ oxidase is a major source of ROS. Oxidative stress depletes nitric oxide (NO) and causes endothelial dysfunction which initiates arteriosclerosis. In a previous study, we found that oxidation of tetrahydrobiopterin by ROS, such as peroxynitrite, results in the formation of dihydrobiopterin, which inactivates the function of a cofactor for NO synthase [27-29]. This finding suggests that reduction in the availability of tetrahydrobiopterin uncouples NO synthase, leading to decreases in bioavailable $\mathrm{NO}$ and further increases in the formation of $\mathrm{O}_{2}^{-}$. In the present study, $\mathrm{Olm} / \mathrm{Azl}$ decreased NAD(P)H oxidase activity in glomeruli and the aortic vascular wall. As a result, this Olm/ Azl combination may protect endothelial function and may offer a significant clinical benefit. Angiotesin II is an important blood pressure-regulating hormone although at the same time it progresses renal dysfunction by inducing $\mathrm{NAD}(\mathrm{P}) \mathrm{H}$ oxidase activity. Thus, Olm sup- 
pressed ROS production by inhibiting the RAS pathway. However, the effect of Azl on the RAS and/or renin-angiotensin-aldosterone system is unclear. On the other hand, HCTZ had no effect on antioxidative stress and moreover has been reported to abolish the anti-atherosclerotic effect of quinapril [30]. Further research is required to define the precise role of low-dose diuretics combined with ARBs for improving blood pressure control and long-term cardiovascular outcomes.

In our study, Olm/Azl decreased heart rate and renal norepinephrine concentration more than did Olm/ HCTZ. In general, antihypertensive treatment with a CCB elicits reflex activation of the sympathetic nervous system, one of the major adverse effects of this class of antihypertensives, which increases the risk of cardiovascular events. In addition, CCBs may activate the RAS and increase insulin resistance and sympathetic nerve activation. Sympathetic nervous activity is increased in patients with CKD [31] and plays an important and distinct role in renal disease-associated hypertension. Indeed, sympathetic activation is of crucial importance for both the raised blood pressure and the high morbidity and mortality of end-stage renal disease. Increased heart rate is reported to be associated with a higher incidence of cardiovascular disease [32, 33]. Azl is a dihydropyridine CCB with the unique ability to suppress systemic sympathetic nerve activity [34]. HCTZ increases sympathetic activity and consequently heart rate by decreasing body fluid volume. Ishimitsu et al. [35] demonstrated in a clinical study that Olm combined with Azl suppressed heart rate, inflammation, and oxidative stress. Meanwhile, catecholamines directly increase $\mathrm{NAD}(\mathrm{P}) \mathrm{H}$ oxidase activity by stimulating $\alpha_{1^{-}}$and $\beta_{2}$-receptors [36, 37]. $\beta_{1}$-Receptor antagonists improve endothelial function and reduce vascular oxidative stress by $\mathrm{NAD}(\mathrm{P}) \mathrm{H}$ oxidase [38]. We reported that a $\beta_{1}$-stimulator directly induces NAD $(\mathrm{P}) \mathrm{H}$ oxidase activity in glomeruli and that renal denervation improves glomerlar injury via suppressed sympathetic nerve activity [18].

Several experimental studies have already demonstrated the efficacy of Olm/Azl combination therapy in animal disease models. Suzuki et al. [39] reported that co-administration of Olm/Azl synergistically blunts oxidative stress and enhances the beneficial effects of each drug in slowing the development of atherosclerosis in apolipoprotein E-deficient mice. Jinno et al. [40] also reported that Azl could inhibit vascular injury and enhance the vasculoprotective effects of Olm in a polyethylene cuff-induced vascular injury in mice. In the present study, we showed that Olm/Azl but not Olm/HCTZ effectively reduces ROS production and protects endothelial function to a similar degree as high-dose Olm treatment. Moreover, in clinical research, the combination of Olm/Azl has been reported to have advantages over Olm/HCTZ with respect to avoiding sympathetic activation, stimulation of the renin-angiotensin-aldosterone system, and oxidative stress in patients with moderate hypertension [35]. Therefore, the combination of Olm and Azl may be effective for long-term antihypertensive therapy aimed at reducing the risk of cardiovascular disease.

We have shown in this study that Olm/Azl and Olm/ HCTZ decreased proteinuria to the same degree in an animal model of metabolic syndrome. However, only Olm/Azl improved podocyte injury and glycocalyx degradation, as revealed by decreased expression of desmin and increased staining of WGA, as much as High-Olm. On the other hand, Olm/HCTZ decreased proteinuria but did not protect against glomerular injury. Podocytes and slit diaphragms play key roles in maintaining the integrity of normal glomerular permeability, as does the glycocalyx in the glomerulus [20]. Podocyte injury (podocytopathy) is involved in the many forms of human and experimental kidney diseases leading to endstage renal disease. Addition of HCTZ to an ARB might decrease proteinuria by reducing renal blood flow. The antiproteinuric effect in this case may not be associated with direct protection of the glomerular barrier function. By contrast, combination of an ARB and CCB probably reduces proteinuria through amelioration of glomerular injuries. This hypothesis is supported by our finding that $\mathrm{Olm} / \mathrm{Azl}$ but not $\mathrm{Olm} / \mathrm{HCTZ}$ improves podocyte injury, as revealed by desmin staining, and decreases oxidative stress by suppressing $\mathrm{NAD}(\mathrm{P}) \mathrm{H}$ oxidase activity.

\section{Conclusion}

The present results demonstrate that monotherapy with high-dose Olm, combination therapy with Olm and Azl, and combination of Olm and HCTZ exert a similar antiproteinuric effect. The Olm/Azl combination is superior to the $\mathrm{Olm} / \mathrm{HCTZ}$ combination in terms of reducing the risk of glomerular and vascular injuries caused by oxidative stress. These data suggest that the combination of Olm with Azl as well as high-dose Olm are more effective than Olm/HCTZ in the treatment of hypertension and reduction of the risk of renal and cardiovascular events. 


\section{Acknowledgments}

This work was supported by the KAKENHI, a Grant-in-Aid for Scientific Research (C) (No. 21591047) to Naoki Kashihara. We thank Ms. Etsuko Yorimasa and Ms. Asuka Maeda for animal care, and Ms. Satomi Hanada and Ms. Keiko Ehara for help with the in vitro assays.

\section{Disclosure Statement}

No conflicts of interest to disclose.

\section{References}

-1 Fuentes R, Ilmaniemi N, Laurikainen E, Tuomilehto J, Nissinen A: Hypertension in developing economies: a review of populationbased studies carried out from 1980 to 1998 . J Hypertens 2000;18:521-529.

$\checkmark 2$ Coresh J, Selvin E, Stevens LA, Manzi J, Kusek JW, Eggers P, Van Lente F, Levey AS: Prevalence of chronic kidney disease in the United States. JAMA 2007;298:2038-2047.

$>3$ Fan YY, Baba R, Nagai Y, Miyatake A, Hosomi N, Kimura S, Sun GP, Kohno M, Fujita M, Abe Y, Nishiyama A: Augmentation of intrarenal angiotensin ii levels in uninephrectomized aldosterone/salt-treated hypertensive rats; renoprotective effects of an ultrahigh dose of olmesartan. Hypertens Res 2006;29:169-178.

4 Brenner BM, Cooper ME, de Zeeuw D, Keane WF, Mitch WE, Parving $\mathrm{HH}$, Remuzzi G, Snapinn SM, Zhang Z, Shahinfar S: Effects of losartan on renal and cardiovascular outcomes in patients with type 2 diabetes and nephropathy. N Engl J Med 2001;345: 861-869.

5 Dickerson JE, Hingorani AD, Ashby MJ, Palmer CR, Brown MJ: Optimisation of antihypertensive treatment by crossover rotation of four major classes. Lancet 1999;353: 2008-2013.

-6 Turnbull F, Neal B, Ninomiya T, Algert C, Arima H, Barzi F, Bulpitt C, Chalmers J, Fagard R, Gleason A, Heritier S, Li N, Perkovic V, Woodward M, MacMahon S: Effects of different regimens to lower blood pressure on major cardiovascular events in older and younger adults: meta-analysis of randomised trials. BMJ 2008;336:1121-1123.

$\checkmark 7$ Ravandi A, Teo KK: Blocking the renin-angiotensin system: dual- versus mono-therapy. Expert Rev Cardiovasc Ther 2009;7:667674.

$>8$ Nemeth Z, Kokeny G, Godo M, Mozes M, Rosivall L, Gross ML, Ritz E, Hamar P: Increased renoprotection with ace inhibitor plus aldosterone antagonist as compared to monotherapies - the effect on podocytes. Nephrol Dial Transplant 2009;24:36403651.

$\checkmark 9$ Waanders F, Vaidya VS, van Goor H, Leuvenink $H$, Damman K, Hamming I, Bonventre JV, Vogt L, Navis G: Effect of renin-angiotensin-aldosterone system inhibition, dietary sodium restriction, and/or diuretics on urinary kidney injury molecule-1 excretion in nondiabetic proteinuric kidney disease: a post-hoc analysis of a randomized controlled trial. Am J Kidney Dis 2009;53:16-25.

10 Jamerson K, Weber MA, Bakris GL, Dahlof B, Pitt B, Shi V, Hester A, Gupte J, Gatlin M, Velazquez EJ: Benazepril plus amlodipine or hydrochlorothiazide for hypertension in high-risk patients. N Engl J Med 2008;359: 2417-2428.

-11 Yamaguchi Y, Yamada K, Yoshikawa N, Nakamura K, Haginaka J, Kunitomo M: Corosolic acid prevents oxidative stress, inflammation and hypertension in SHR/NDmcrcp rats, a model of metabolic syndrome. Life Sci 2006;79:2474-2479.

-12 Fan YY, Kohno M, Nakano D, Ohsaki H, Kobori H, Suwarni D, Ohashi N, Hitomi H, Asanuma K, Noma T, Tomino Y, Fujita T, Nishiyama A: Cilnidipine suppresses podocyte injury and proteinuria in metabolic syndrome rats: possible involvement of $\mathrm{N}$-type calcium channel in podocyte. J Hypertens 2010;28:1034-1043.

13 Fujimoto S, Satoh M, Horike H, Hatta H, Haruna Y, Kobayashi S, Namikoshi T, Arakawa S, Tomita N, Kashihara N: Olmesartan ameliorates progressive glomerular injury in subtotal nephrectomized rats through suppression of superoxide production. Hypertens Res 2008;31:305-313.

14 Fujimoto S, Satoh M, Nagasu H, Horike H, Sasaki T, Kashihara N: Azelnidipine exerts renoprotective effects by improvement of renal microcirculation in angiotensin II infusion rats. Nephrol Dial Transplant 2009;24: 3651-3658.

15 Namikoshi T, Satoh M, Tomita N, Haruna Y, Kobayashi S, Komai N, Sasaki T, Kashihara $\mathrm{N}$ : Pioglitazone ameliorates endothelial dysfunction in obese rats with nephropathy. Biochem Biophys Res Commun 2007;361: 835-840.

16 Kobayashi S, Satoh M, Namikoshi T, Haruna Y, Fujimoto S, Arakawa S, Komai N, Tomita N, Sasaki T, Kashihara N: Blockade of serotonin 2a receptor improves glomerular endothelial function in rats with streptozotocin-induced diabetic nephropathy. Clin Exp Nephrol 2008;12:119-125.

17 Satoh M, Ogita H, Takeshita K, Mukai Y, Kwiatkowski DJ, Liao JK: Requirement of $\mathrm{Racl}$ in the development of cardiac hyper- trophy. Proc Natl Acad Sci USA 2006;103: 7432-7437.

18 Nagasu H, Satoh M, Kuwabara A, Yorimitsu D, Sakuta T, Tomita N, Kashihara N: Renal denervation reduces glomerular injury by suppressing $\mathrm{NAD}(\mathrm{P}) \mathrm{H}$ oxidase activity in Dahl salt-sensitive rats. Nephrol Dial Transplant 2010;25:2889-2898.

19 Namikoshi T, Tomita N, Satoh M, Haruna Y, Kobayashi S, Komai N, Sasaki T, Kashihara $\mathrm{N}$ : Pioglitazone enhances the antihypertensive and renoprotective effects of candesartan in Zucker obese rats fed a high-protein diet. Hypertens Res 2008;31:745-755.

20 Kuwabara A, Satoh M, Tomita N, Sasaki T, Kashihara N: Deterioration of glomerular endothelial surface layer induced by oxidative stress is implicated in altered permeability of macromolecules in Zucker fatty rats. Diabetologia 2010;53:2056-2065.

21 Haruna Y, Morita Y, Komai N, Yada T, Sakuta T, Tomita N, Fox DA, Kashihara N: Endothelial dysfunction in rat adjuvant-induced arthritis: vascular superoxide production by $\mathrm{NAD}(\mathrm{P}) \mathrm{H}$ oxidase and uncoupled endothelial nitric oxide synthase. Arthritis Rheum 2006;54:1847-1855.

-22 Shinomiya K, Mizushige K, Fukunaga M, Masugata H, Ohmori K, Kohno M, Senda S: Antioxidant effect of a new calcium antagonist, azelnidipine, in cultured human arterial endothelial cells. J Int Med Res 2004;32: 170-175.

23 Yamagishi S, Inagaki Y, Nakamura K, Imaizumi T: Azelnidipine, a newly developed long-acting calcium antagonist, inhibits tumor necrosis factor- $\alpha$-induced interleukin- 8 expression in endothelial cells through its antioxidative properties. J Cardiovasc Pharmacol 2004;43:724-730.

24 Tanifuji C, Suzuki Y, Geot WM, Horikoshi S, Takahashi H, Tomino Y: Beneficial effects of combination therapy with olmesartan and azelnidipine in murine polycystic kidneys. Kidney Blood Press Res 2009;32:239-249.

25 Keidar S, Kaplan M, Pavlotzky E, Coleman R, Hayek T, Hamoud S, Aviram M: Aldosterone administration to mice stimulates macrophage NADPH oxidase and increases atherosclerosis development: a possible role for angiotensin-converting enzyme and the receptors for angiotensin II and aldosterone. Circulation 2004;109:2213-2220. 
-26 Griendling KK, Harrison DG: Out, damned dot: studies of the NADPH oxidase in atherosclerosis. J Clin Invest 2001;108:14231424.

27 Satoh M, Fujimoto S, Haruna Y, Arakawa S, Horike H, Komai N, Sasaki T, Tsujioka K, Makino H, Kashihara N: NAD(P)H oxidase and uncoupled nitric oxide synthase are major sources of glomerular superoxide in rats with experimental diabetic nephropathy. Am J Physiol Renal Physiol 2005;288:F1144F1152.

28 Satoh M, Haruna Y, Fujimoto S, Sasaki T, Kashihara N: Telmisartan improves endothelial dysfunction and renal autoregulation in Dahl salt-sensitive rats. Hypertens Res 2010;33:135-142.

-29 Satoh M, Fujimoto S, Arakawa S, Yada T, Namikoshi T, Haruna Y, Horike H, Sasaki T, Kashihara N: Angiotensin ii type 1 receptor blocker ameliorates uncoupled endothelial nitric oxide synthase in rats with experimental diabetic nephropathy. Nephrol Dial Transplant 2008;23:3806-3813.

>30 Fonseca FA, Ihara SS, Izar MC, Silva EP, Kasinski N, Lopes IE, Pinto LE, Paiva TB, Tufik S, de Paola AA, Carvalho AC: Hydrochlorothiazide abolishes the anti-atherosclerotic effect of quinapril. Clin Exp Pharmacol Physiol 2003;30:779-785.
31 Neumann J, Ligtenberg G, Klein II, Koomans HA, Blankestijn PJ: Sympathetic hyperactivity in chronic kidney disease: pathogenesis, clinical relevance, and treatment. Kidney Int 2004;65:1568-1576.

32 Gillman MW, Kannel WB, Belanger A, D'Agostino RB: Influence of heart rate on mortality among persons with hypertension: the Framingham Study. Am Heart J 1993; 125:1148-1154.

33 Puchler K, Laeis P, Stumpe KO: Blood pressure response, but not adverse event incidence, correlates with dose of angiotensin II antagonist. J Hypertens Suppl 2001;19:S4148

34 Shokoji T, Fujisawa Y, Kiyomoto H, Rahman M, Sun GP, Fan YY, Kimura S, Kohno M, Abe Y, Nishiyama A: Effects of a new calcium channel blocker, azelnidipine, on systemic hemodynamics and renal sympathetic nerve activity in spontaneously hypertensive rats. Hypertens Res 2005;28:1017-1023.

35 Ishimitsu T, Numabe A, Masuda T, Akabane T, Okamura A, Minami J, Matsuoka H: Angiotensin-II receptor antagonist combined with calcium channel blocker or diuretic for essential hypertension. Hypertens Res 2009; 32:962-968.

36 Faber JE, Szymeczek CL, Salvi SS, Zhang H: Enhanced $\alpha_{1}$-adrenergic trophic activity in pulmonary artery of hypoxic pulmonary hypertensive rats. Am J Physiol Heart Circ Physiol 2006;291:H2272-H2281.
37 Bleeke T, Zhang H, Madamanchi N, Patterson C, Faber JE: Catecholamine-induced vascular wall growth is dependent on generation of reactive oxygen species. Circ Res 2004;94:37-45.

38 Oelze M, Daiber A, Brandes RP, Hortmann M, Wenzel P, Hink U, Schulz E, Mollnau H, von Sandersleben A, Kleschyov AL, Mulsch A, Li H, Forstermann U, Munzel T: Nebivolol inhibits superoxide formation by NADPH oxidase and endothelial dysfunction in angiotensin II-treated rats. Hypertension 2006; 48:677-684.

39 Suzuki J, Iwai M, Li Z, Li JM, Min LJ, Ide A, Yoshii T, Oshita A, Mogi M, Horiuchi M: Effect of combination of calcium antagonist, azelnidipine, and AT1 receptor blocker, olmesartan, on atherosclerosis in apolipoprotein E-deficient mice. J Hypertens 2005;23: 1383-1389.

40 Jinno T, Iwai M, Li Z, Li JM, Liu HW, Cui TX, Rakugi H, Ogihara T, Horiuchi M: Calcium channel blocker azelnidipine enhances vascular protective effects of AT1 receptor blocker olmesartan. Hypertension 2004;43: 263-269. 